\title{
Efficacy of Corrosion Inhibitive Properties of Gum exudates of Azadirachta indica on Carbon steel in $1 \mathrm{~N}$ hydrochloric acid
}

\author{
M. MALARVIZHI ${ }^{1}$ and J. MALLIKA ${ }^{2 *}$ \\ 'Department of Chemistry, Sri GVG Visalakshi College for Women, Udumalpet-642128, Tamil Nadu, India. \\ ${ }^{2}$ Department of Chemistry, PSG College of Arts and Science, Coimbatore-641014, Tamil Nadu, India. \\ *Corresponding author E-mail: jmchempsg2016@gmail.com \\ http://dx.doi.org/10.13005/ojc/340534
}

(Received: February 02, 2018; Accepted: August 08, 2018)

\begin{abstract}
Corrosion mitigation of carbon steel by neem gum (gum exudates of Azadirachta indica) was investigated in $1 \mathrm{~N} \mathrm{HCl}$ medium. Effect of temperature and immersion period towards the mitigation process is studied using weight loss method.Electrochemical studies indicate that corrosion reaction is inhibited by adsorption of gum molecules. Adsorption process is consistent with Langmuir isotherm. The inhibitor behaves as mixed type for carbon steel corrosion in $1 \mathrm{~N} \mathrm{HCl}$. Surface morphology studies reveal adsorption on the metal surface.
\end{abstract}

Keywords: Corrosion inhibition, Gum exudates of Azadirachta indica, Carbon steel, HCl, SEM.

\section{INTRODUCTION}

Carbon steel (CS) is extensively used in constructions as well as in industrial applications ${ }^{1,2}$. Under different working environments, $\mathrm{CS}$ is liable to undergo corrosion. Though many ways are available for corrosion inhibition of metals, use of inhibitors to arrest the corrosion process is considered the best ${ }^{3}$. Many synthetic organic compounds are reported as corrosion inhibitors ${ }^{4}$. Due to their environment and health constraints ${ }^{5}$, use of natural plant products as corrosion inhibitors are extensively studied ${ }^{6}$. Since gum exudates of plants and trees have the potential to act as corrosion inhibitors, many naturally occurring gum exudates were studied as corrosion inhibitors $^{7-9}$. The complexity of constituents, tendency to form complexes with metal ions and eco-friendly nature make the gum exudates good corrosion inhibitors $^{10}$.

A survey of literature showed that the neem gum ie., gum exudates of Azadirachta indica (GAl) has not been employed towards corrosion mitigation of carbon steel in hydrochloric acid medium. Azadirachta indica gum is reported to contain D- glucose, D-glucoronic acid, L-arabinose, L-fucose, mannose, xylose, rhamnose, D-glucosamine, aldobiuronic acid, serine, threonine and aspartic acid ${ }^{11,12}$. Considering the above mentioned advantages of gum exudates towards corrosion inhibition and the presence of complex organic constituents in GAI, the current investigation is aimed to examine 
the possibility of gum exudates of Azadirachta indica as a CS corrosion inhibitor in $\mathrm{HCl}$ solution. The inhibition efficiency has been tested using the following methods: weight loss, Polarization and AC impedance methods. The effect of temperature (303$328 \pm 1 \mathrm{~K})$ and immersion time 1,2,4,5,6 and $8 \mathrm{~h}$ on the corrosion performance of CS was also analyzed using weight loss method. The carbon steel surface in the absence and presence of inhibitor has been examined using scanning electron microscopy.

\section{MATERIALS AND METHOD}

Neem gum obtained from local area was purified. Analar grade sulphuric acid solution was used as corrosive medium. All solutions were prepared using double distilled water. The Carbon steel coupons of composition $0.37 \%$ C, $0.680 \%$ Mn, $0.230 \%$ Si, $0.160 \%$ Cu, $0.077 \%$ Cr, $0.059 \%$ $\mathrm{Ni}, 0.015 \%$ S, $0.011 \% \mathrm{Ti}, 0.009 \%$ Co, remaining Fe having dimensions of $25 \times 10 \times 1 \mathrm{~mm}$ was used to carry out weight loss experiments on the basis of ASTM practice standard G-3114.

Following equations (1),(2) and (3) were used for calculation purpose.

Corrosion rate $(\mathrm{mmpy})=87.6 \times \frac{\mathrm{W}}{\rho \mathrm{At}}$

Inhibition efficiency $(\%)=\frac{\mathrm{W}_{0}-\mathrm{W}_{\mathrm{i}}}{\mathrm{W}_{0}} \times 100$

Surface Coverage $\quad \theta=1-\frac{\mathrm{W}_{\mathrm{i}}}{\mathrm{W}_{\mathrm{o}}}$

Where $W, \rho, A, t, W_{i}$ and $W_{o}$ represents weight loss in $\mathrm{g}$, density of $\mathrm{CS}$ coupon in $\mathrm{g} \mathrm{cm}^{3}$, area of the coupon in $\mathrm{cm}^{2}$, time of immersion in $h$, loss of weight in inhibited and free acid solutions respectively.

The electrochemical tests were carried out using a conventional three electrode system at room temperature. Along with the CS working electrode, saturated calomel electrode and platinum electrodes were used as reference and counter electrodes respectively. Scan rate in the case of polarization studies was $1 \mathrm{mV} \mathrm{s}^{-1}$ and the potential range studied was +200 to $-200 \mathrm{mV}$. Frequency range of $10 \mathrm{KHz}$ to $0.01 \mathrm{~Hz}$ was set for impedance studies while $10 \mathrm{mV}$ amplitude AC signals were employed for OCP with prior immersion of 30 minutes. $Z_{\text {view }}$ software was used to obtain impedance data as Nyquist plots from which the Rct values were found. JEOL-JSM-35-CF SEM instrument was employed to analyze the exterior surface of inhibited and uninhibited carbon steel specimens.

\section{RESULTS AND DISCUSSION}

\section{Effect of inhibitor concentration}

Effect of GAl on the corrosion process of $\mathrm{CS}$ in $1 \mathrm{~N} \mathrm{HCl}$ medium was studied at $303 \pm 1 \mathrm{~K}$ using gravimetric measurements for different immersion periods up to 8 hours. Table 1 shows the calculated values of corrosion rate (CR), inhibition efficiency (IE) and surface coverage $(\theta)$. Analysis of Table 1 indicates that there was a gradual decrease in corrosion rate with increase in GAl concentration showing the concentration dependence of corrosion rates. Beyond 80 ppm concentration, no considerable inhibition performance of GAI was observed which specifies the optimum concentration as $80 \mathrm{ppm}$. The gum showed the maximum inhibition efficiency of $83.04 \%$ for $1 \mathrm{~h}$ immersion period at an optimum concentration of $80 \mathrm{ppm}$. Primarily the protection act was due to GAI accumulation on to the CS surface which reduces the acid contact of the metal. The high outcome for relatively longer immersion period could be due to insoluble filmy coat or corrosion product formed on CS surface which prevents the penetration of $\mathrm{Cl}^{-}$ions of aggressive medium and inward diffusion of oxygen, thereby decreasing the corrosion rate ${ }^{16}$.

\section{Effect of Immersion Period}

Stability of GAI on CS surface is evaluated by carrying out weight loss measurements in the inhibited and uninhibited solutions for immersion periods of $1,2,4,5,6$ and $8 \mathrm{~h}$ at $303 \mathrm{~K}$ and the obtained corrosion parameters are given in the Table1. On close inspection of the table it can be understood that efficiency of the inhibitor increased with immersion period revealing the protective layer formation on CS due to strong adsorption of GAI. There was a linear relationship of weight loss with immersion period. As the immersion period and the GAl concentration increases, a chemical mode of adsorption was expected ${ }^{17}$. The inhibitor efficiency increases gradually attaining maximum for $5 \mathrm{~h}$ immersion time suggesting that the stability and effectiveness of the inhibitor withstands over a period of 5 hour. After an immersion period of $5 \mathrm{~h}$, it can be noticed that the inhibition efficiency slowly started to decrease. 
Table 1: Effect of different concentrations of GAI on CS in $1 \mathrm{~N} \mathrm{HCl}$ for various immersion periods at $303 \mathrm{~K}$

\begin{tabular}{|c|c|c|c|c|c|c|c|c|c|}
\hline $\begin{array}{c}\mathrm{C} \\
\mathrm{ppm}\end{array}$ & $\begin{array}{c}1 \mathrm{~h} \\
\mathrm{CR} \\
\mathrm{mmpy}\end{array}$ & $\begin{array}{l}\text { I E } \\
(\%)\end{array}$ & $\theta$ & $\begin{array}{c}2 \mathrm{~h} \\
\mathrm{CR} \\
\mathrm{mmpy}\end{array}$ & $\begin{array}{l}\text { I E } \\
(\%)\end{array}$ & $\theta$ & $\begin{array}{c}4 \mathrm{~h} \\
\mathrm{CR} \\
\mathrm{mmpy}\end{array}$ & $\begin{array}{l}\text { I E } \\
(\%)\end{array}$ & $\theta$ \\
\hline Blank & 46.11 & & & 49.27 & & & 52.21 & & \\
\hline 5 & 32.1 & 30.39 & 0.3039 & 31.87 & 35.32 & 0.3532 & 31.08 & 40.48 & 0.4048 \\
\hline 10 & 28.03 & 39.22 & 0.3922 & 26.44 & 46.33 & 0.4633 & 25.65 & 50.87 & 0.5087 \\
\hline 20 & 23.51 & 49.02 & 0.4902 & 21.47 & 56.42 & 0.5642 & 21.36 & 59.09 & 0.5909 \\
\hline 40 & 18.08 & 60.78 & 0.6078 & 16.95 & 65.6 & 0.656 & 15.93 & 69.48 & 0.6948 \\
\hline 60 & 14.47 & 68.63 & 0.6863 & 13.11 & 73.39 & 0.7339 & 11.98 & 77.06 & 0.7706 \\
\hline 80 & 13.56 & 70.59 & 0.7059 & 9.49 & 80.73 & 0.8073 & 7.8 & 85.06 & 0.8506 \\
\hline 100 & 14.92 & 67.65 & 0.6765 & 9.27 & 81.19 & 0.8119 & 7.57 & 85.5 & 0.855 \\
\hline 120 & 13.11 & 71.57 & 0.7157 & 9.04 & 81.65 & 0.8165 & 7.23 & 86.15 & 0.8615 \\
\hline C & $5 \mathrm{~h}$ & & & $6 \mathrm{~h}$ & & & $8 \mathrm{~h}$ & & \\
\hline ppm & $\begin{array}{c}\text { CR } \\
\text { mmpy }\end{array}$ & $\begin{array}{l}\text { I E } \\
(\%)\end{array}$ & $\theta$ & $\begin{array}{c}\text { CR } \\
\text { mmpy }\end{array}$ & $\begin{array}{l}\text { I E } \\
(\%)\end{array}$ & $\theta$ & $\begin{array}{c}\text { CR } \\
\text { mmpy }\end{array}$ & $\begin{array}{l}\text { I E } \\
(\%)\end{array}$ & $\theta$ \\
\hline Blank & 55.07 & & & 58.26 & & & 60.03 & & \\
\hline 5 & 28.4 & 48.43 & 0.4843 & 32.04 & 45 & 0.45 & 34.67 & 42.24 & 0.4224 \\
\hline 10 & 25.16 & 54.31 & 0.5431 & 29.61 & 49.18 & 0.4918 & 31.82 & 46.99 & 0.4699 \\
\hline 20 & 20.87 & 62.11 & 0.6211 & 24.18 & 58.49 & 0.5849 & 31.1 & 48.19 & 0.4819 \\
\hline 40 & 14.09 & 74.42 & 0.7442 & 21.53 & 63.05 & 0.6305 & 28.07 & 53.24 & 0.5324 \\
\hline 60 & 11.38 & 79.34 & 0.7934 & 19.49 & 66.54 & 0.6654 & 27.3 & 54.52 & 0.5452 \\
\hline 80 & 9.34 & 83.04 & 0.8304 & 18.36 & 68.48 & 0.6848 & 25.09 & 58.21 & 0.5821 \\
\hline 100 & 9.42 & 82.9 & 0.829 & 15.93 & 72.65 & 0.7265 & 22.78 & 62.05 & 0.6205 \\
\hline 120 & 9.57 & 82.63 & 0.8263 & 14.92 & 74.39 & 0.7439 & 22.92 & 61.82 & 0.6182 \\
\hline
\end{tabular}

Thermodynamic considerations

Influence of temperature on inhibition behavior of $\mathrm{GAl}$ for $\mathrm{CS}$ corrosion in $1 \mathrm{~N} \mathrm{HCl}$ was studied at the temperatures $303 \mathrm{~K}, 313 \mathrm{~K}$ and $323 \mathrm{~K}$ and the obtained results were shown in Table 2 . With increase in temperature, corrosion rate increases in the presence and absence of GAI due to increase in the kinetic energy of the reacting entities. Corrosion rate at any given concentration decreases in case of inhibited acid solution compared to that of uninhibited solution in all temperature range studied It was as a result of mitigating effect of the gum on the corrosion reaction of CS. With increase in temperature, a linear but a slight increase in inhibition efficiency was observed. At all temperatures studied, inhibition performance lowered or remained similar after 80 ppm GAI. The adsorption process may be either physical or chemical adsorption ${ }^{18}$. The fact is decided by nature and structure of the inhibitor, $\mathrm{pH}$ and temperature of the system and character and charge of the metal ${ }^{18}$.

Based on the Arrhenius equation ${ }^{19}$, the apparent activation energy $\left(E^{*}{ }_{a}\right)$ was evaluated using frequency factor $\mathrm{A}$ from the equation (4). A plot (Fig. 1) was made between log CR and 1/T resulting in the slope of $-E^{*}{ }_{a} / 2.303 R$ and intercept $A$ from which $E_{a}$ and $A$ were obtained . The enthalpy and entropy parameters $\Delta \mathrm{S}^{*}$ and $\Delta \mathrm{H}^{*}$ were obtained using equation 5 . A transition state curve between $\log (\mathrm{CR} / \mathrm{T})$ versus $1 / \mathrm{T}$ is plotted. This plot Fig. 2 gave a straight line with slope $\left(-\Delta \mathrm{H}^{\star} / 2.303 \mathrm{R}\right)$ and intercept $\log (\mathrm{R} / \mathrm{Nh})+\Delta \mathrm{S}^{*} / 2.303 \mathrm{R}$.

$$
\begin{aligned}
& \log \mathrm{CR}=\log \mathrm{A}-\frac{\mathrm{E}_{\mathrm{a}}^{*}}{2.303 \mathrm{RT}} \\
& \mathrm{CR}=\left(\frac{\mathrm{RT}}{\mathrm{Nh}}\right) \exp \left(\frac{\Delta \mathrm{S}^{*}}{\mathrm{R}}\right) \exp \left(\frac{-\Delta \mathrm{H}^{*}}{\mathrm{RT}}\right)
\end{aligned}
$$

Table 3 displays the obtained values for $E_{a}, \Delta H^{*}$ and $\Delta S^{*}$. Activation energy $\left(E_{a}\right)$ for free acid solution is $72.83 \mathrm{KJmol}^{-1}$ which decreases to $58.26 \mathrm{KJmol}^{-1}$ in the presence of GAI. This indicates that GAI is adsorbed chemically which in turn reduces the corrosion rate ${ }^{20-22}$. For any given concentration $\mathrm{E}_{\mathrm{a}}$ value is larger than $\Delta \mathrm{H}^{*}$ value. Decrease in $\Delta \mathrm{H}^{*}$ value for the inhibited solution compared to blank also supports the chemical nature of adsorption. 
Endothermic nature of CS dissolution is confirmed by positive enthalpy values $\left(\Delta H^{\star}\right)^{23,24}$. The free acid solution has entropy value $\left(\Delta \mathrm{S}^{\star}\right)$ of $19.17 \mathrm{JK}^{-1} \mathrm{~mol}^{-1}$ which decreases up to a maximum of $-38.30 \mathrm{JK}^{-1}$ $\mathrm{mol}^{-1}$ in the presence of GAl which actually signifies the conversion of reactants to activated complexes ${ }^{25}$.

Table 2: Corrosion parameters for different concentrations of GAl on CS in $1 \mathrm{~N} \mathrm{HCl}$ at $303 \mathrm{~K}, 313 \mathrm{Kand} 323 \mathrm{~K}$ for $1 \mathrm{~h}$ immersion period

\begin{tabular}{lccccccccc}
\hline $\begin{array}{l}\text { C } \\
\text { ppm }\end{array}$ & CR mmpy $\begin{array}{c}\text { 303K } \\
\text { IE } \\
(\%)\end{array}$ & $\theta$ & CR mmpy $\begin{array}{c}313 \mathrm{~K} \\
\text { I E } \\
(\%)\end{array}$ & $\theta$ & CR mmpy & $\begin{array}{c}\text { 323K } \\
\text { I } \%)\end{array}$ & $\theta$ \\
\hline Blank & 46.11 & & & 150.08 & & & 265.8 & & \\
5 & 32.1 & 30.39 & 0.3039 & 101.26 & 32.53 & 0.3253 & 174.94 & 34.18 & 0.3418 \\
10 & 28.03 & 39.22 & 0.3922 & 86.79 & 42.17 & 0.4217 & 150.98 & 43.2 & 0.432 \\
20 & 23.51 & 49.02 & 0.4902 & 74.59 & 50.3 & 0.503 & 125.22 & 52.89 & 0.5289 \\
40 & 18.08 & 60.78 & 0.6078 & 56.51 & 62.35 & 0.6235 & 95.38 & 64.12 & 0.6412 \\
60 & 14.47 & 68.63 & 0.6863 & 43.85 & 70.78 & 0.7078 & 75.49 & 71.6 & 0.716 \\
80 & 13.56 & 70.59 & 0.7059 & 41.14 & 72.59 & 0.7259 & 65.55 & 75.34 & 0.7534 \\
100 & 14.92 & 67.65 & 0.6765 & 40.68 & 72.89 & 0.7289 & 60.57 & 77.21 & 0.7721 \\
120 & 13.11 & 71.57 & 0.7157 & 41.59 & 72.29 & 0.7229 & 63.29 & 76.19 & 0.7619 \\
\hline
\end{tabular}

Table 3: Activation parameters for $\mathrm{CS}$ in $1 \mathrm{~N} \mathrm{HCl}$ in the absence and presence of GAl in the temperature range of $303 \mathrm{~K}$ - 323K for $1 \mathrm{~h}$ immersion period

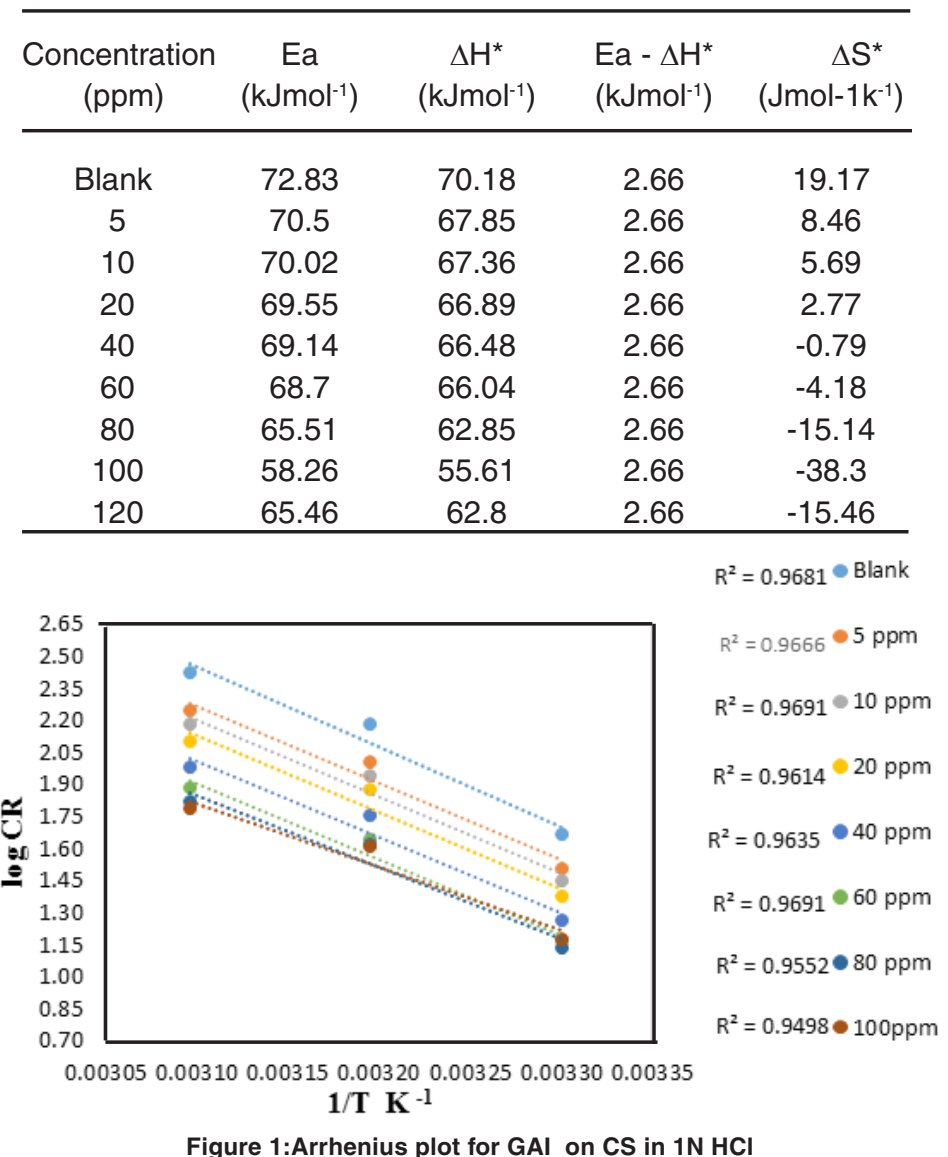

Figure 1:Arrhenius plot for GAI on $\mathrm{CS}$ in $1 \mathrm{~N} \mathrm{HCl}$ 


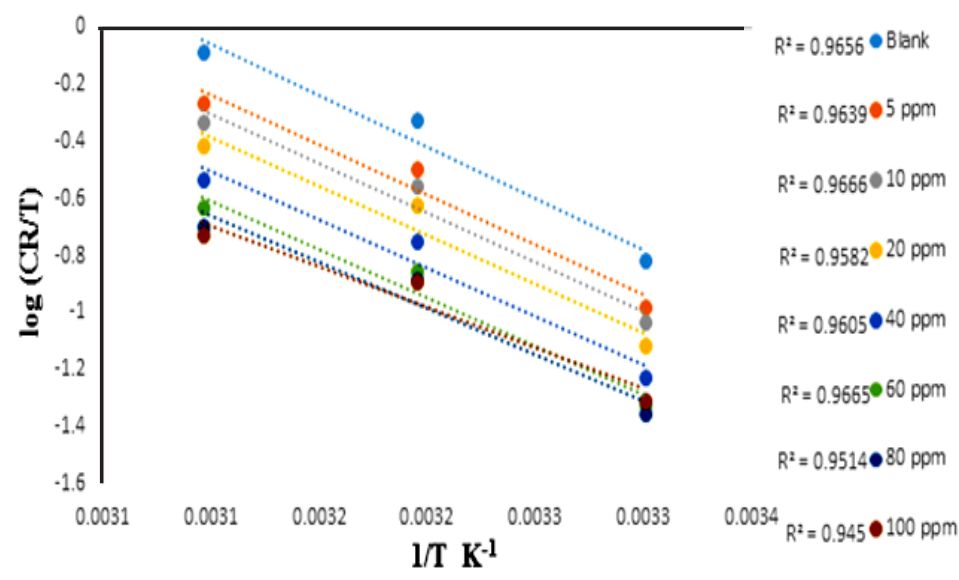

Fig. 2. Transition State plot GAI Carbon steel $1 \mathrm{~N} \mathrm{HCl}$

\section{Adsorption Isotherm}

Generally the adsorption process of organic molecules over the metal surface depends on chemical composition of the organic compound, temperature range of study, and electrochemical potential on metal|26,27 Adsorption isotherms signify the mechanistic path of adsorption. In the present study the Langmuir isotherm model was found as best fitting one. Langmuir isotherm equation relates equilibrium constant $\mathrm{K}_{\mathrm{ads}}$ and concentration as in equation (6) and $\Delta G_{a d s}$, free energy of adsorption is calculated from the equation (7)

$$
\begin{aligned}
& \frac{C}{\theta}=\frac{1}{\mathrm{~K}_{\mathrm{ads}}}+C \\
& \mathrm{~K}=-\log \mathrm{C}_{\mathrm{H}_{2} \mathrm{O}}-\left(\frac{\Delta \mathrm{G}_{\text {ads }}^{\circ}}{2.303 \mathrm{RT}}\right)
\end{aligned}
$$

Langmuir adsorption plots obtained at different temperatures with various concentrations of GAl is shown in Fig. 3. Strong adsorption is evident from the strong correlation coefficients $R^{2}>0.99$ at all temperatures. Calculated $\Delta \mathrm{G}_{\mathrm{ads}}$ is presented in Table 4. Slope values also confirms the validity of the Langmuir model. Negative $\Delta G_{\text {ads }}$ values shows

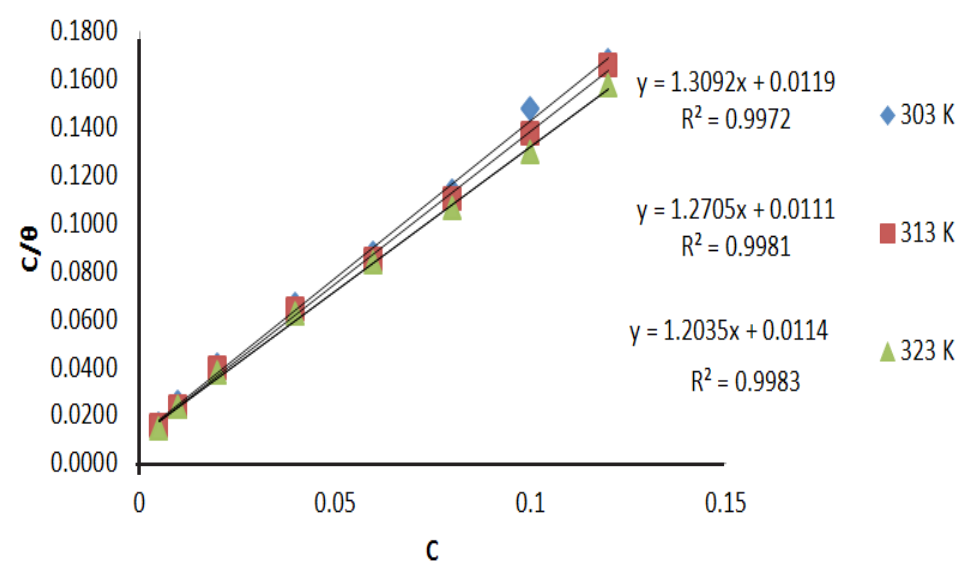

Fig. 3. Langmuir adsorption Isotherm

Table 4: Adsorption parameters for the different concentration of GAI on CS in $1 \mathrm{~N} \mathrm{HCl}$ in the temperature range of $303-323 \mathrm{~K}$

\begin{tabular}{lccc}
\hline $\begin{array}{l}\text { Temperature } \\
\mathrm{K}\end{array}$ & $\begin{array}{c}\text { Slope Equilibrium constant } \\
\mathrm{n}\end{array}$ & $\begin{array}{c}-\Delta \mathrm{G}_{\text {ads }}^{\mathrm{O}} \text { ads } \\
\mathrm{kJmol}^{-1}\end{array}$ \\
\hline 303 & 1.3 & 76.527 & -21.28 \\
313 & 1.2 & 93.52 & -21.47 \\
323 & 1.2 & 112.138 & -21.39 \\
\hline
\end{tabular}

that the adsorption process is spontaneous ${ }^{28}$. Generally, $\Delta \mathrm{G}_{\mathrm{ads}}$ around $-20 \mathrm{~kJ} / \mathrm{mol}$ is suggestive of physisorption and around $-40 \mathrm{~kJ} / \mathrm{mol}$ is said to be chemisorption ${ }^{29}$. So it is implicit that $\Delta \mathrm{G}_{\mathrm{ads}}$ values presented in Table 4 is reflective of physical nature of adsorption. But the $E_{a}$ values reveal that a little of chemical bonding may also be involved in the adsorption process. 
Electrochemical considerations

\section{Electrochemical polarization studies}

Polarization potential curves applied for the assessment of corrosion mitigation effect of $\mathrm{GAl}$ on $\mathrm{CS}$ specimen in $1 \mathrm{~N} \mathrm{HCl}$ for $4 \mathrm{~h}$ immersion period is presented in Fig. 4 By usual extrapolation method, corrosion current $I_{\text {corr }}$ and potential $E_{\text {corr }}$ is evaluated and the inhibition efficiency was assessed by equation (8).

$$
I E(\%)=\frac{I_{\operatorname{corr}(0)}-I_{\operatorname{corr}(i)}}{I_{\operatorname{corr}(0)}} \times 100
$$

From Fig. 4 , it was clear that corrosion rate decreases in the presence of GAI as a consequence of production of lower current densities by both anionic dissolution of metals and cationic hydrogen evolution reaction. Change in the tafel constants prove that GAl affects both anodic and cathodic reaction. Table 5 shows the electrochemical parameters $\mathrm{I}_{\text {corr }}$ and $\mathrm{E}_{\text {corr }} \mathrm{IE}(\%)$, Tafel constants $b_{a}$ and $b_{c}$. From the table, it is evident that there is decrease in corrosion rate in GAl inhibited solution compared to blank solution. Decrease in $I_{\text {corr }}$ value shows the retardation of electrochemical reactions. In addition absence of significant change in $\mathrm{E}_{\text {corr }}$ values is indication of mixed mode type ${ }^{30}$. The inhibition efficiencies obtained in this method follows the similar pattern observed in gravimetric experiments.

Table 5 : Polarization data of $\mathrm{CS}$ in $1 \mathrm{~N} \mathrm{HCl}$ in the presence and absence of GAI

\begin{tabular}{cccccc}
\hline $\begin{array}{c}\text { Concentration } \\
(\mathrm{ppm})\end{array}$ & $\begin{array}{c}\mathrm{I}_{\text {corr }} \\
\left.(\mathrm{mA} \mathrm{cm})^{-2}\right)\end{array}$ & $\begin{array}{c}\mathrm{E}_{\text {corr }} \\
(\mathrm{Mv} / \mathrm{SCE})\end{array}$ & $\begin{array}{c}\mathrm{b}_{\mathrm{a}} \\
\left(\mathrm{mV} \mathrm{dec}^{-1}\right)\end{array}$ & $\begin{array}{c}\mathrm{b}_{\mathrm{c}} \\
\left(\mathrm{mV} \mathrm{dec}^{-1}\right)\end{array}$ & $\mathrm{IE}(\%)$ \\
\hline Blank & 763 & -471.28 & 84.4 & 133 & - \\
40 & 312 & -433.2 & 69 & 150 & 59.11 \\
60 & 268 & -436.26 & 72 & 138 & 64.88 \\
100 & 234 & -434.91 & 77 & 140 & 69.33 \\
\hline
\end{tabular}

\section{AC Impedance Spectroscopy Studies}

In order to study the adsorption nature of $\mathrm{CS}$ in $1 \mathrm{~N} \mathrm{HCl}$ at room temperature, impedence responses were recorded after $4 \mathrm{~h}$ immersion for free acid and inhibited test solutions. which is shown in the Fig. 5. This shows Nyquist plots increasing in diameter of semi-circles with GAl concentration which is indicative of the fact that GAl adsorption on to the metal hinders the corrosion process. Difference in the shape of the semicircles can be explained with reference to non-homogeneity of the surface and roughness of the metal ${ }^{31}$. Charge transfer resistance $\left(R_{c t}\right)$, double layer capacitance $\left(C_{d l}\right)$ and inhibition efficiency values were presented in Table 6. On evaluation of Table 6 shows, $C_{d l}$ values were found to decrease with increase in $R_{c t}$. This may be attributed to the fact that the green inhibitor gets adsorbed as thin protective film on the surface of the electrode. The $\mathrm{C}_{d l}$ value of uninhibited solution is $45.3 \times 10^{-3} \mu \mathrm{F} \mathrm{cm}^{-2}$ which decreases to 20.8 $X 10^{-3} \mu \mathrm{F} \mathrm{cm}^{-2}$ on addition of $100 \mathrm{ppm}$ GAl. Thus there was a decrease in $C_{d l}$ values with increase in concentration. This can be accounted by any of the two factors: lowering of dielectric constant and increase of thickness in double layer capacitance ${ }^{32}$. Thus electrical capacity is decreased through the displacement of ions and water molecules on the surface interface ${ }^{33}$. Shapes of the semicircle with and without inhibitor look alike indicating an unaltered corrosion mechanism on the addition of GAl.

Table 6:AC Impedance data of $\mathrm{CS}$ in $1 \mathrm{~N} \mathrm{HCI}$ in the presence and absence of GAl

\begin{tabular}{cccc}
\hline $\begin{array}{c}\text { Concentration } \\
(\mathrm{ppm})\end{array}$ & $\begin{array}{c}\mathrm{R}_{\mathrm{ct}} \\
\left(\Omega \mathrm{cm}^{-2}\right)\end{array}$ & $\begin{array}{c}\mathrm{C}_{\mathrm{dl}} \\
(\mu \mathrm{F} \mathrm{cm})^{-2}\end{array}$ & IE (\%) \\
\hline Blank & 12.1 & 45.1 & - \\
40 & 51.3 & 29.7 & 76.41 \\
60 & 84.8 & 23.1 & 85.73 \\
100 & 101.3 & 20.8 & 88.05 \\
\hline
\end{tabular}

\section{Scanning Electron Microscopy}

To validate film formation, SEM images of CS coupons exposed to inhibited and uninhibited solutions were documented. Fig. 6a, $6 \mathrm{~b}$ and $6 \mathrm{c}$ show freshly recorded SEM images of polished CS surface, CS surface exposed to uninhibited solution and CS surface exposed to $100 \mathrm{ppm}$ of GAl respectively.

Figure 6 a shows plain clear surface, while Fig. 6 b depicts severely corroded surface due to acid attack and Fig. $6 \mathrm{c}$ represents smooth surface with some scattered pits. This changes in the surface of the CS specimen is a supportive feature of formation of adsorbed film. Thus the addition of GAI to $1 \mathrm{~N} \mathrm{HCl}$ has reduced the corrosion of carbon steel specimen significantly. 


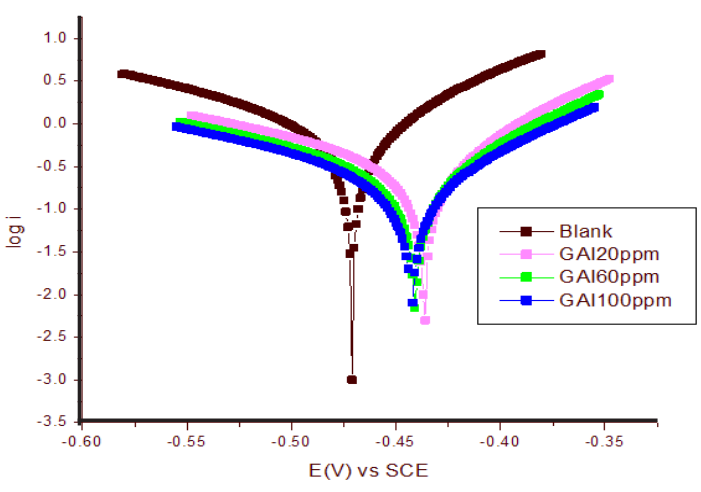

Fig. 4. Polarisation curves for $\mathrm{CS}$ in $1 \mathrm{~N} \mathrm{HCI}$

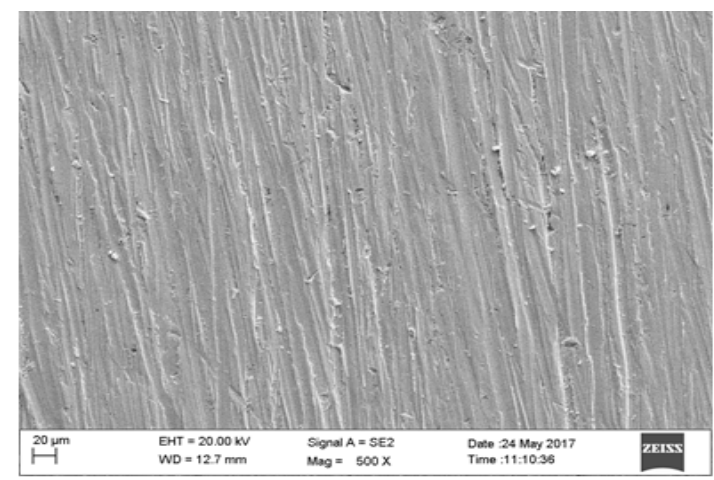

(a) polished surface

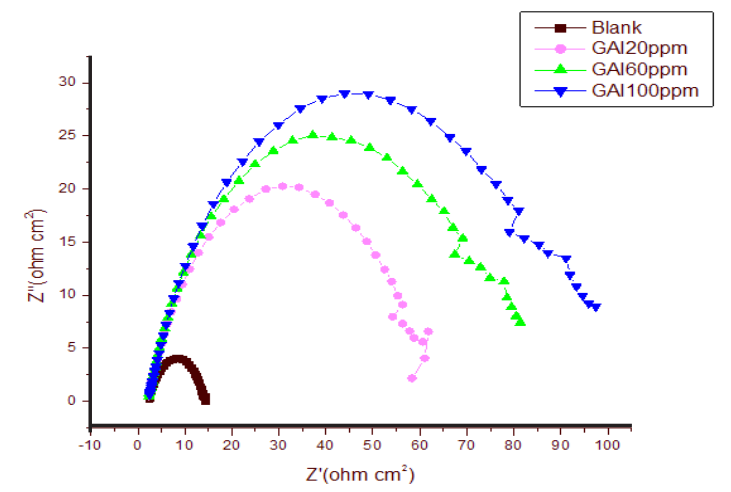

Fig. 5. Nyquist plots of $\mathrm{CS}$ in $1 \mathrm{~N} \mathrm{HCl}$

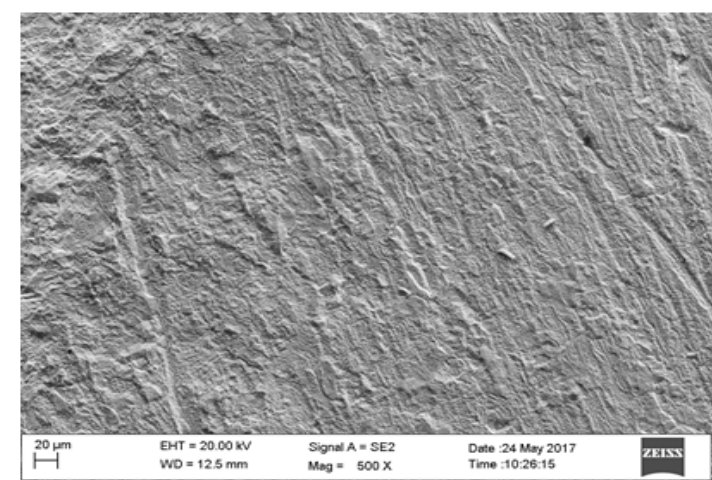

(b) after immersion in $1 \mathrm{~N} \mathrm{HCl} \mathrm{solution}$

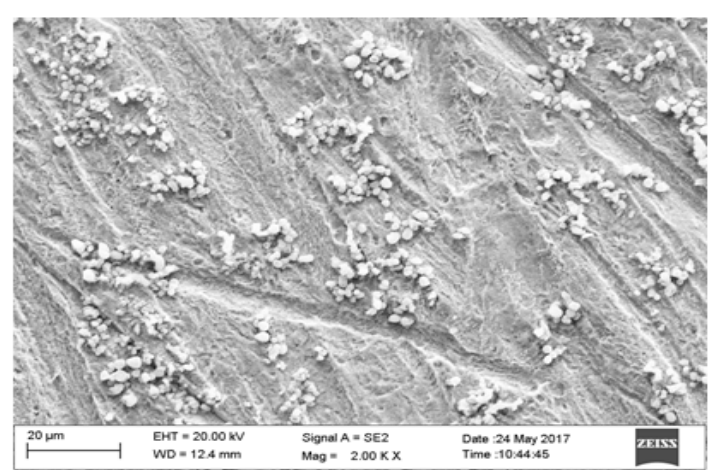

(c) after immersion in $100 \mathrm{ppm}$ GAl

\section{CONCLUSION}

- $\quad$ GAl shows significant corrosion inhibition for CS in hydrochloric acid medium.

- With increase in temperature, inhibition efficiency increases for $1 \mathrm{~h}$ immersion period.

- Inhibition process takes place through adsorption mechanism

Langmuir is the best fit isotherm.

- Spontaneity of the adsorption process is shown by thermodynamic parameters.
- The polarization measurements evince the mixed mode nature of GAI.

- $\quad$ The SEM analysis supports protective film formation on carbon steel.

\section{ACKNOWLEDGEMENT}

The authors are thankful to PSG College of Arts and Science, Coimbatore and Sri GVG Visalakshi College for Women, Udumalpet for supporting with the lab facilities. 


\section{REFERENCES}

1. Deyab, M.A. Corros. Sci., 2007, 49, 23152328.

2. Hamdy, A.; Nour Sh. El-Gendy. Egypt. J. Petr., 2013, 22, 17-25.

3. Trabanelli, G.; Corr., 1991, 47, 410-419.

4. Abhay Singh. SSRG Inter. J. App.Chem., 2017, 5, 21-25.

5. Ostovari, A.; Hoseinieh, M.; Peikari, M.; Shadizadeh, S.R.; Hashemi, S. J. Corro. Sci., 2009, 51, 1935-1949.

6. Janaina Cardozo da Rocha.; José Antônio da Cunha Ponciano Gomes.; Eliane D’Elia. Corros Sci., 2010, 52, 2341-2348.

7. Umoren, S.A.; Obot, I. B.; Ebenso, E.E. J. Chem., 2008, 5(2), 355-364.

8. Buchweishaija, J.; Mhinzi, G.S. Port. Electrochim. Acta., 2008, 26, 257-265.

9. Abdallah, M. Port. Electrochim. Acta., 2004, 22, 161-175.

10. Eddy, N.O.; Ameh, P.; Gimba, C.E.; and Ebenso, E.E. Int. J. Electrochem. Sci., 2012, 7, 7425-7439.

11. Allman, M.A.; Pena M.M.; Peng. D. Eur. J. Clin. Nutr., 1995, 49, 169-178.

12. Anderson, D.M.W.; Hendrie, A. Carbohyd. Res., 1971, 20, 259-268.

13. Mukerjee, S.; Srivastava, H.C. J. Am. Chem. Soc., 1955, 77, 422- 423.

14. ASTM practice standard G-31.; Standard practice for laboratory immersion corrosion testing of metals.; ASTM International. 2004.

15. Granese, S. L., Rosales, B. M.; Ociede, C., and Zerbino J.O. Corros Sci., 1992, 33, 1439 - 1453.

16. Al-Fozan, S.A.; Malik, A. U. Desalination., 2008, 228, 61-67.

17. Trabanelli, G., Mansfeld, F. (Ed.), Corrosion Inhibitors, Chemical Industries: Corrosion Mechanism., 1987, 28(3), 119-163.
18. Blaedel, W. J.; Meloche, V.W.; Elementary Quantitative Analysis; Theory and Practice, Second Edition, Harper \& Row, Publishers, Incorporated, 49 East 33rd Street, New York 16, New York., 1963, 684-698.

19. Rani, P. D.; Selvaraj, S. Journal of Phytology., 2010, 2(11), 58-64.

20. Umoren, S A.; Ogbobe, O.; Ebenso E E. J Appl Polym Sci., 2007, 105, 3363-3370.

21. Orubite, K .O.; Oforka, N.C. J Mater. Lett., 2004, 58, 1768-1772.

22. El-Etre, A .Y. J. Appl. Surf. Sci., 2006, 252, 8521-8525.

23. Szauer, T.; Brandt, A. Electrochim. Acta., 1981, 26, 1209-1217.

24. Dahmani, M.; Et-Touhami, A.; Al-Deyab, S.; Hammouti, S.; Bouyanzer, B. J.Electrochem. Sci., 2010, 5 , 1060-1069.

25. Saliyan, V.R.; Adhikari, A.V. Bull. Mater. Sci., 2007, 31, 699-711.

26. Gerengi, H.; Goksu, H.; Slepski, P. Mater. Res., 2014, 17(1) 255-264.

27. Oguzie, E. E. Corros. Sci., 2007, 49(3) 1527-1539.

28. Ali, S. A.; Saeed, M. T.; Rahman, S. U. Corros. Sci., 2003, 45, 253-266.

29. Ali, S.A.; El-Shareef, A.M.; Al-Ghamdi, R.F.; Saeed, M.T. Corros. Sci., 2005, 47, 2659-2678.

30. Muralidharan, S.; Quraishi, M.; Iyer, S. V. K. Corros. Sci., 1995, 37, 1739 -1750.

31. Bentiss, F.; Jama, C.; Mernari, B. Corr. Sci., 2009, 8, 1628-1635.

32. Outirite, M.; Lagrenee, M.; Lebrini, M.; Traisnel, M., Jama, C.; Vezin, H.; Bentiss, F. Electrochim. Acta., 2010, 55, 1670-1681.

33. Lagrenée, M.; Mernari B., Bouanis, M.; Traisnel, M., Bentiss, F.Corros. Sci., 2002, 44, 573-588. 